\title{
Article \\ Parameter Sensitivity Analysis on Dynamic Coefficients of Partial Arc Annular-Thrust Aerostatic Porous Journal Bearings
}

\author{
Pyung Hwang ${ }^{1, *}$, Polina Khan ${ }^{2}$ and Seok-Won Kang ${ }^{1, *}$ \\ 1 Department of Automotive Engineering, Yeungnam University, Gyeongsan 38541, Korea \\ 2 Melentiev Energy Systems Institute of Siberian Branch of Russian Academy of Sciences, \\ 664033 Irkutsk, Russia; polinakhan@isem.irk.ru \\ * Correspondence: phwang@yu.ac.kr (P.H.); swkang@yu.ac.kr (S.-W.K.)
}

\section{check for}

updates

Citation: Hwang, P.; Khan, P.; Kang, S.-W. Parameter Sensitivity Analysis on Dynamic Coefficients of Partial Arc Annular-Thrust Aerostatic Porous Journal Bearings. Appl. Sci. 2021, 11, 10791. https://doi.org/ 10.3390/app112210791

Academic Editors:

Terenziano Raparelli,

Federico Colombo, Andrea Trivella and Luigi Lentini

Received: 30 September 2021 Accepted: 11 November 2021 Published: 15 November 2021

Publisher's Note: MDPI stays neutral with regard to jurisdictional claims in published maps and institutional affiliations.

Copyright: (c) 2021 by the authors. Licensee MDPI, Basel, Switzerland. This article is an open access article distributed under the terms and conditions of the Creative Commons Attribution (CC BY) license (https:// creativecommons.org/licenses/by/ $4.0 /)$.

\begin{abstract}
Aerostatic bearings are widely used in high-precision devices. Partial arc annular-thrust aerostatic porous journal bearings are a prominent type of aerostatic bearings, which carry both radial and axial loads and provide high load-carrying capacity, low air consumption, and relatively low cost. Spindle shaft tilting is a resource-demanding challenge in numerical modeling because it involves a 3D air flow. In this study, the air flow problem was solved using a COMSOL software, and the dynamic coefficients for tilting degrees of freedom were obtained using finite differences. The obtained results exhibit significant coupling between the tilting motion in the $\mathrm{x}$-and $\mathrm{y}$-directions: cross-coupled coefficients can achieve $20 \%$ of the direct coefficient for stiffness and $50 \%$ for damping. In addition, a nonlinear behavior can be expected, because the tilting motion within $3^{\circ}$, tilting velocities within $0.0012^{\circ} / \mathrm{s}$, and relative eccentricity of 0.2 have effects as large as $20 \%$ for direct stiffness and $100 \%$ for cross-coupled stiffness and damping. All dynamic coefficients were fitted with a polynomial of eccentricity, tilting, and tilting velocities in two directions, with a total of six parameters. The resulting fitting coefficient tables can be employed for the fast dynamic simulation of the rotor shaft carried on the proposed bearing type.
\end{abstract}

Keywords: aerostatic journal bearings; porous bearing; annular-thrust bearing; numerical simulation; finite element method; dynamic coefficients; eccentricity; tilting; tilting velocity; partial arc

\section{Introduction}

Porous aerostatic bearings are widely used in machinery, owing to their relatively high load-carrying capacity and low air consumption [1-3]. Similar to other types of aerostatic bearings, owing to their high accuracy and zero contamination, they are suitable for high-precision devices. In addition, the friction drag of a porous aerostatic bearing is low $[4,5]$, its motion accuracy is higher than that of a conventional orifice-type aerostatic bearing $[5,6]$, and its load thresholds at high rotation speeds are the highest among other types of aerostatic bearings [5,7]. The production of porous materials with desirable permeabilities is relatively complicated. However, the amount of porous material required can be reduced via design optimization [8].

The optimal governing equations required for porous air bearing analysis remain under discussion. Zhong et al. [9] experimentally determined Ergun's equation coefficients for the pressure drop in sintered metal porous media for air bearings. Belforte et al. [10] experimentally verified Forchheimer's law for porous air bearing applications. Zhong et al. [11] verified the accuracy of Forchheimer's law for air flow through sintered metal porous media and Darcy's law, under slight pressure drops. Recently, it has been reported that a deep learning-based approach can be employed for high-precision and low-cost analysis of the 3D flow state inside a porous material [12].

Various numerical methods and engineering packages have been adopted for air pressure calculations in porous bearings. Huang et al. [13] analyzed the pressure in a porous conveyor air bearing using the FLUENT software. Cui et al. [14] used FLUENT 
software to numerically analyze the effect of manufacturing errors on the load-carrying capacity and stiffness of an annular-thrust porous aerostatic bearing. In addition, the deformation of porous thrust bearings was numerically investigated based on the fluidsolid interaction method by Wang et al. [15]. Van Ostayen et al. [16] used the COMSOL software for active aerostatic bearing analysis. Hwang and Khan [17] conducted 3D finite element analysis, while Plante et al. [18] proposed the shed 1D generalized flow theory. Otsu et al. [19] and Hosokawa et al. [8] used the FDM.

Several papers [19-22] deal with the numerical calculation of stiffness and damping coefficients corresponding to eccentricity or parallel shaft displacement (Figure 1a). However, insufficient data are available on stiffness and damping for shaft tilting (Figure 1b) in porous air bushing. Cui et al. [14,23] analyzed the non-flatness effect of the air-bearing surface on the stiffness and damping of an aerostatic porous bearing, which is computationally similar to modeling the tilting.
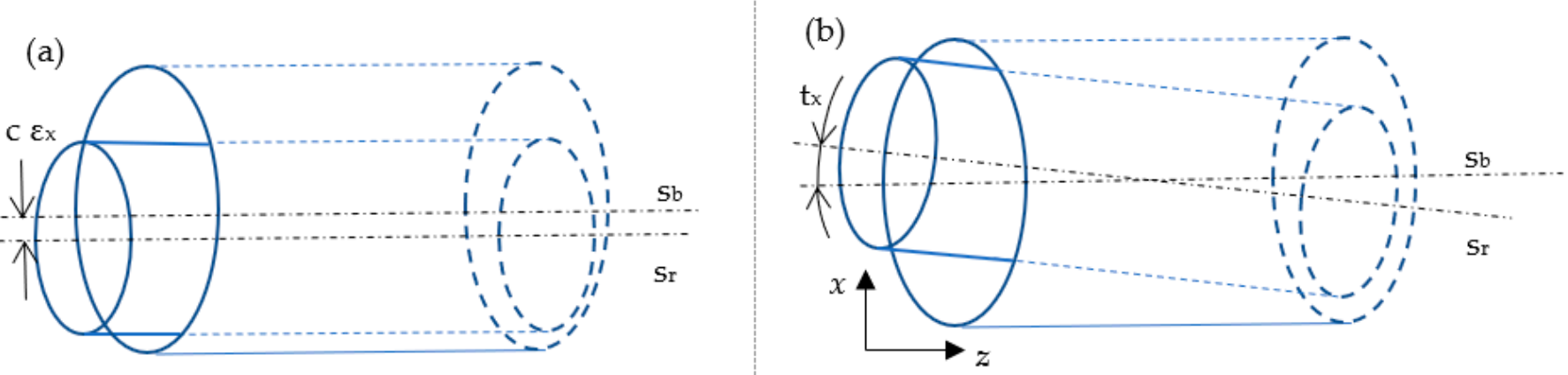

Figure 1. Two spindle motion modes: (a) eccentricity; (b) tilting. $s_{b}$ and $s_{r}$ denote the bearing and rotor axes, respectively.

The rotor in ultraprecision devices is usually supported by journal and thrust bearings, which share a common air supply system but separate porous pads [14,23]. Annularthrust bearings share the same porous pad carrying loads in both the annular and thrust directions (Figure 2). This dual role decreases the manufacturing cost while triggering flow coupling [23-27]. A partial arc bearing has a higher load-carrying capacity but lower stiffness than a full-arc bearing [27].

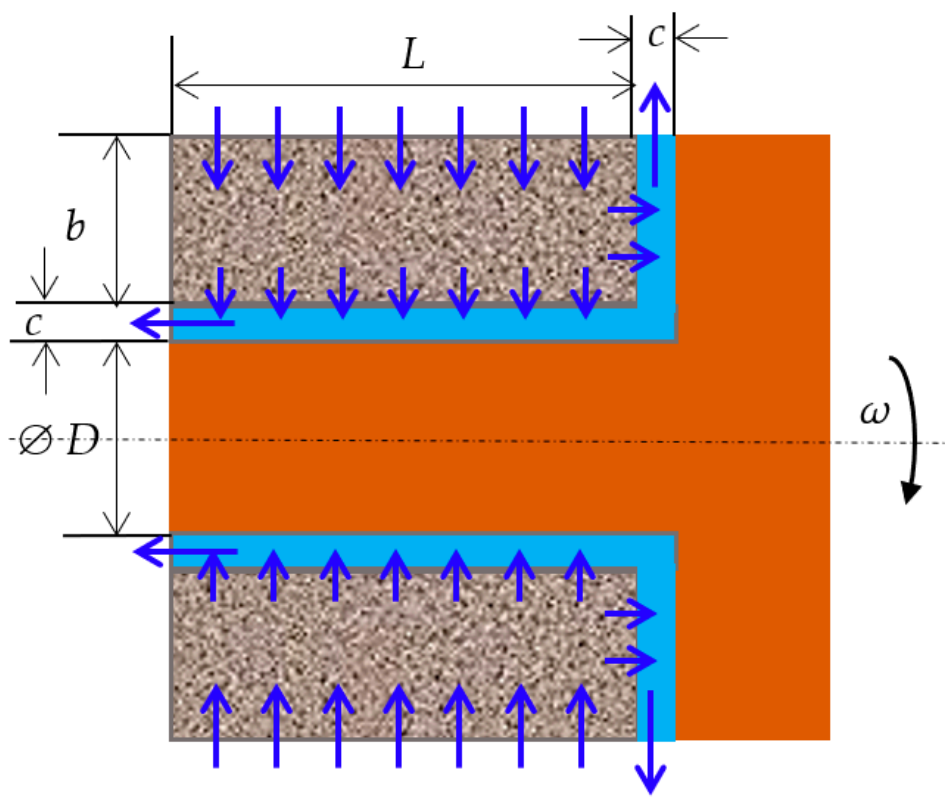

Figure 2. Annular-thrust porous aerostatic bearing. 
The numerical modeling of the rotor motion, including the effect of shaft tilting, as well as the modeling of a partial arc annular-thrust porous aerostatic bearing is substantially time-consuming, because it requires a 3D air flow solution. Dynamic modeling can be performed in a less resource-consuming manner if the full bearing model is replaced with stiffness and damping coefficients. The nonlinear dynamic motion can be modeled, provided the influences of eccentricity, tilting, and velocities on the dynamic coefficients are included. In this study, the air flow in the porous pad and air lubrication film between the porous pad and solid surface of the shaft were numerically modeled using the COMSOL Multiphysics ${ }^{\circledR}$ software. The pressure distribution and total forces and moments were calculated for low eccentricity, low tilting angles, and tilting speeds. The stiffness and damping coefficients were determined using finite differences.

\section{Materials and Methods}

The porous air bearing was modeled using the COMSOL Multiphysics software, "Darcy's law", and "Thin-Film Flow, Shell" modules. Here, the static solution is sufficient in determining the response of the displacement and velocity of the spindle. In addition, the porous bushing is a hollow cylinder parallel to the z-axis with a cut sector $\alpha$. Figure 3 illustrates the different boundary conditions.

(a)

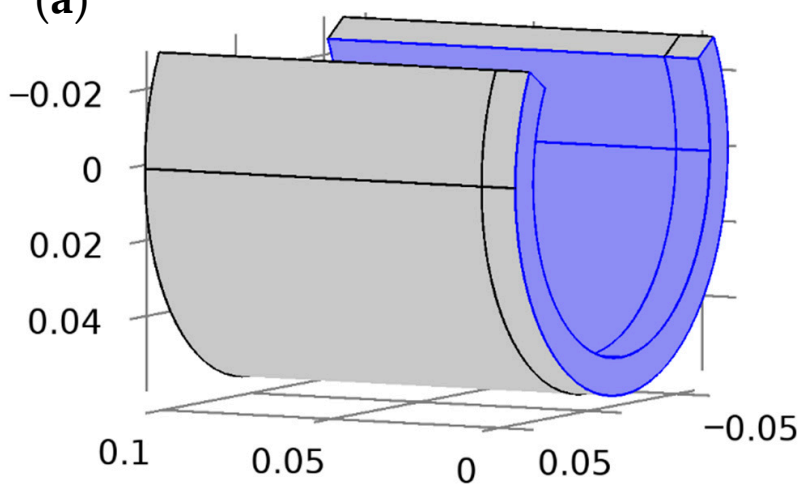

(c)

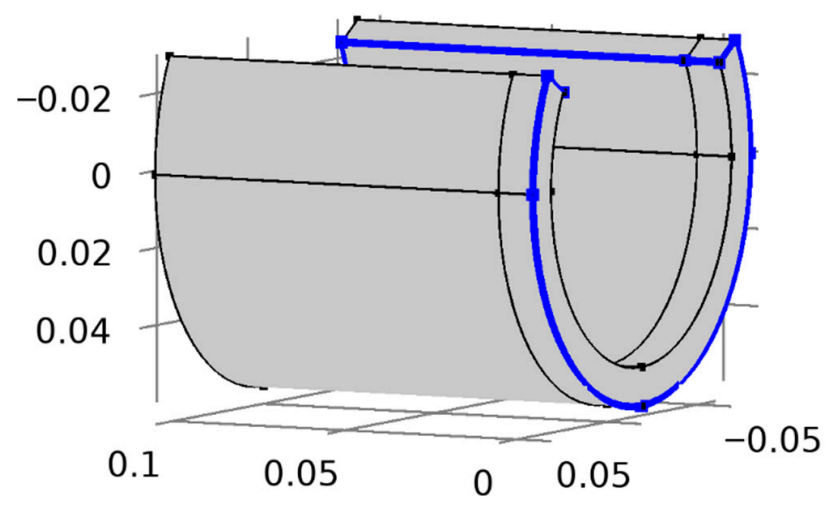

(b)

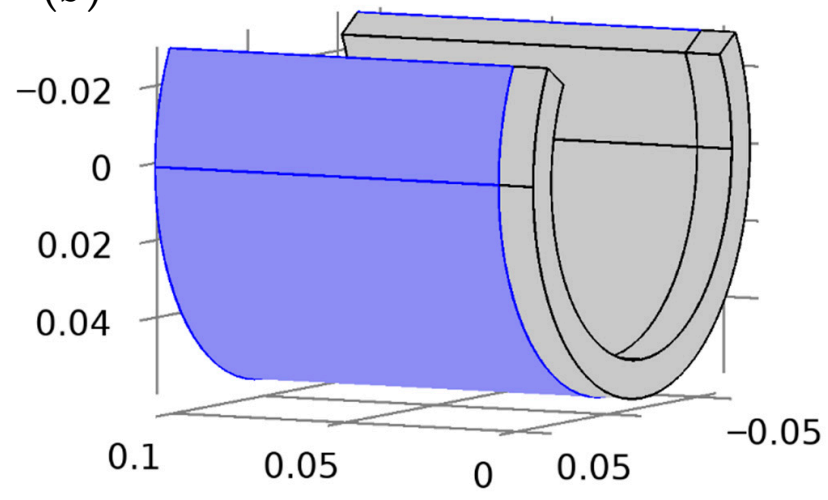

(d) 0.05

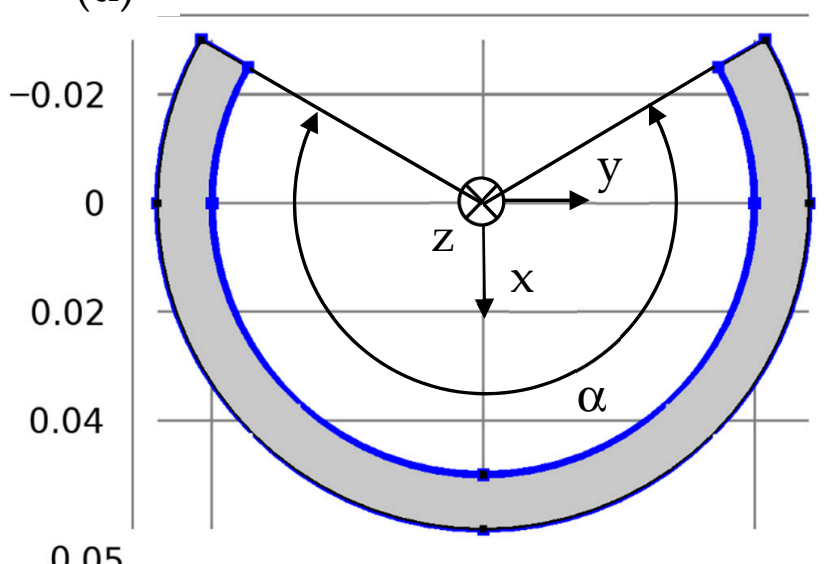

Figure 3. Porous pad boundaries: (a) airbearing surface carrying both radial and axial loads; (b) air supply surface; (c) outflow to atmospheric pressure; (d) outflow to atmospheric pressure in $x y$-plane with axes and bearing partial arc. 
The pressure in the porous pad is modeled with the "Darcy's law" module:

$$
-\nabla\left(\rho \frac{\kappa}{\mu} \nabla p\right)=0
$$

where $p, \rho, \kappa$, and $\mu$ denote the air pressure, air density, permeability coefficient, and dynamic viscosity of air, respectively. $\nabla$ is the gradient operator in three-dimensional space. The pressure at the air-bearing surface (see Figure 3a) is modeled with the "thin-film flow, shell" module:

$$
\nabla_{t}\left(\rho h\left(\frac{1}{2} v_{t}-\frac{h^{3}}{12 \mu} \nabla_{t} p_{f}\right)\right)=-\rho \frac{\partial}{\partial t} h+Q
$$

where $p_{f}, h, v_{t}$, and $Q$ represent the air film pressure, air film thickness, tangential spindle surface velocity, and air flux, respectively. $\nabla_{\mathrm{t}}$ is the gradient operator in the twodimensional space of the air film surface and $\nabla$ is the partial derivative operator. At the interface between the porous pad and the air-bearing surface, the pressure and air flux must be continuous. In the "Darcy's law" module, the "Pressure" boundary condition is adopted at the surfaces that open to the air lubrication film, which is expressed as:

$$
p=p_{f}
$$

In the "Thin-Film Flow, Shell", the continuity of the air flux is expressed by admittance $\mathrm{Y}$ in the "Perforation" interface, which is expressed as:

$$
Y=\frac{Q \cdot n}{\rho p_{f}}
$$

where $\boldsymbol{n}=\left(n_{x}, n_{y}, n_{z}\right)$ is the air-bearing surface normal vector. The air film thickness in the "Thin-Film Flow, Shell" module depends on the spindle eccentricity $\left(\varepsilon_{x}, \varepsilon_{y}\right)$, tilting $\left(t_{x}, t_{y}\right)$, and tilting velocities $\left(\dot{t}_{x}, \dot{t}_{y}\right)$ (refer to Figure 1 ):

$$
\begin{gathered}
h=c+\boldsymbol{u} \cdot \boldsymbol{n}-\boldsymbol{u} \cdot \nabla_{t} h \\
\frac{\partial}{\partial t} h=\boldsymbol{v} \cdot \boldsymbol{n}-\boldsymbol{v} \cdot \nabla_{t} h \\
\boldsymbol{u}=\left(c \varepsilon_{x}+t_{x}(z-L / 2) ; c \varepsilon_{y}+t_{y}(z-L / 2) ;-t_{x} x-t_{y} y\right) \\
\boldsymbol{v}=\left(-y \omega+\dot{t}_{x}(z-L / 2) ; x \omega+\dot{t}_{y}(z-L / 2) ;-\dot{t}_{x} x-\dot{t}_{y} y\right)
\end{gathered}
$$

where $u$ is the spindle surface displacement, and $v$ is the spindle surface velocity.

The isothermal compressibility of the air was modeled using the user-defined density in both modules. Here, the density is related to the air pressure in the "Variables" block as follows:

$$
\rho=\frac{\rho_{0} p}{p_{0}}
$$

where the subscript 0 refers to the atmospheric conditions, and $p_{0}=1$ bar. The air supply is modeled by another "Pressure" interface in the "Darcy's law" module with a constant pressure of $p_{s}$ (see Figure $3 b$ ). The outflow at the air-bearing edges is given by the "Border" interface in the "Thin-Film Flow, Shell" module with a fixed pressure of $p_{0}$ (see Figure 3c). The other boundaries were sealed.

After the static problem was solved and the air pressure was calculated, the moments in the $x$ and $y$ tilt directions were calculated, using the "Surface Integration" in the "Derived Values" block, according to the following expressions:

$$
M_{x}=\iint p\left(n_{x}(z-L / 2)-n_{z} x\right) d x \prime d y \prime
$$




$$
M_{y}=\iint p\left(n_{y}(z-L / 2)-n_{z} y\right) d x / d y \prime
$$

where $x^{\prime}$ and $y^{\prime}$ are the local coordinates of the air film surface.

Stiffness and damping for tilting degrees of freedom were calculated by using finite differences:

$$
\begin{aligned}
& K_{t x, t x}=-\left(M_{x}\left(\varepsilon_{x}, \varepsilon_{y}, t_{x}+\Delta t_{x}, t_{y}, \dot{t}_{x}, \dot{t}_{y}\right)-M_{x}\left(\varepsilon_{x}, \varepsilon_{y}, t_{x}, t_{y}, \dot{t}_{x}, \dot{t}_{y}\right)\right) / \Delta t_{x} \\
& K_{t x, t y}=-\left(M_{x}\left(\varepsilon_{x}, \varepsilon_{y}, t_{x}, t_{y}+\Delta t_{y}, \dot{t}_{x}, \dot{t}_{y}\right)-M_{x}\left(\varepsilon_{x}, \varepsilon_{y}, t_{x}, t_{y}, \dot{t}_{x}, \dot{t}_{y}\right)\right) / \Delta t_{y} \\
& K_{t y, t x}=-\left(M_{y}\left(\varepsilon_{x}, \varepsilon_{y}, t_{x}+\Delta t_{x}, t_{y}, \dot{t}_{x}, \dot{t}_{y}\right)-M_{y}\left(\varepsilon_{x}, \varepsilon_{y}, t_{x}, t_{y}, \dot{t}_{x}, \dot{t}_{y}\right)\right) / \Delta t_{x} \\
& K_{t y, t y}=-\left(M_{y}\left(\varepsilon_{x}, \varepsilon_{y}, t_{x}, t_{y}+\Delta t_{y}, \dot{x}_{x}, \dot{t}_{y}\right)-M_{y}\left(\varepsilon_{x}, \varepsilon_{y}, t_{x}, t_{y}, \dot{t}_{x}, \dot{t}_{y}\right)\right) / \Delta t_{y} \\
& D_{t x, t x}=-\left(M_{x}\left(\varepsilon_{x}, \varepsilon_{y}, t_{x}, t_{y}, \dot{t}_{x}+\Delta \dot{t}_{x}, \dot{t}_{y}\right)-M_{x}\left(\varepsilon_{x}, \varepsilon_{y}, t_{x}, t_{y}, \dot{t}_{x}, \dot{t}_{y}\right)\right) / \Delta \dot{t}_{x} \\
& D_{t x, t y}=-\left(M_{x}\left(\varepsilon_{x}, \varepsilon_{y}, t_{x}, t_{y}, \dot{t}_{x}, \dot{t}_{y}+\Delta \dot{t}_{y}\right)-M_{x}\left(\varepsilon_{x}, \varepsilon_{y}, t_{x}, t_{y}, \dot{t}_{x}, \dot{t}_{y}\right)\right) / \Delta \dot{t}_{y} \\
& D_{t y, t x}=-\left(M_{y}\left(\varepsilon_{x}, \varepsilon_{y}, t_{x}, t_{y}, \dot{t}_{x}+\Delta \dot{t}_{x}, \dot{t}_{y}\right)-M_{y}\left(\varepsilon_{x}, \varepsilon_{y}, t_{x}, t_{y}, \dot{t}_{x}, \dot{t}_{y}\right)\right) / \Delta \dot{t}_{x} \\
& D_{t y, t y}=-\left(M_{y}\left(\varepsilon_{x}, \varepsilon_{y}, t_{x}, t_{y}, \dot{t}_{x}, \dot{t}_{y}+\Delta \dot{t}_{y}\right)-M_{y}\left(\varepsilon_{x}, \varepsilon_{y}, t_{x}, t_{y}, \dot{t}_{x}, \dot{t}_{y}\right)\right) / \Delta \dot{t}_{y}
\end{aligned}
$$

\section{Results}

The airbearing moments, tilting stiffness, and damping were calculated for $\varepsilon_{x}=0.1$, $0.2,0.3, \varepsilon_{y}=0.0,0.1, t_{x}=-0.003^{\circ},-0.00275^{\circ}, \ldots, 0.003^{\circ}$, and $t_{y}=0.0^{\circ}, 0.00025^{\circ}, \ldots$, $0.003^{\circ}$, respectively; with $p_{s}=8$ bar, bearing length $L=0.11 \mathrm{~m}$, shaft diameter $D=0.1 \mathrm{~m}$, porous cylinder thickness $b=0.01 \mathrm{~m}$, clearance $c=10 \mu \mathrm{m}$, rotation speed $=1000 \mathrm{rpm}$, bearing arc $\alpha=240^{\circ}$, porosity $=0.4$, and permeability $=8.33 \times 10^{-17} \mathrm{~m}^{2}$. The film variation due to tilting in the given range does not exceed $57 \%$ for simultaneous change of $t_{x}$ and $t_{y}$. Together with 30\% variation due to eccentricity, it gives a minimal film thickness of $13 \%$ of clearance, or $1.3 \mu \mathrm{m}$. The air-bearing pressure, forces, and moments were calculated for all combinations of parameters $t_{x}, t_{y}, \varepsilon_{x}$, and $\varepsilon_{y}$, and their combinations with the following pairs of tilting velocity values: $\left(\dot{t}_{x}, \dot{t}_{y}\right) \in\left\{(0,0),\left(\Delta \dot{t}_{x}, 0\right),\left(2 \Delta \dot{t}_{x}, 0\right),\left(0, \Delta \dot{t}_{y}\right),\left(0,2 \Delta \dot{t}_{y}\right)\right\}$. The total number of cases was 13000. The steps in the differences (12-19) were $\Delta t_{x}=$ $\Delta t_{y}=0.00025^{\circ}$, and $\Delta \dot{t}_{x}=\Delta \dot{t}_{y}=0.00573^{\circ} / \mathrm{s}$. The maximum and average absolute errors of the finite differences are presented in Table 1.

Table 1. Finite difference errors.

\begin{tabular}{ccccccccc}
\hline & \multicolumn{3}{c}{ Stiffness $(\mathbf{k N} \cdot \mathbf{m} / \mathbf{r a d})$} & \multicolumn{3}{c}{ Damping $(\mathbf{k N} \cdot \mathbf{m} \cdot \mathbf{s} / \mathbf{r a d})$} \\
& $\boldsymbol{K}_{t x, t x}$ & $\boldsymbol{K}_{t x, t y}$ & $\boldsymbol{K}_{t y, t x}$ & $\boldsymbol{K}_{t y, t y}$ & $\boldsymbol{D}_{t x, t x}$ & $\boldsymbol{D}_{t x, t y}$ & $\boldsymbol{D}_{t y, t x}$ & $\boldsymbol{D}_{t y, t y}$ \\
\hline $\max$ & 0.124 & 0.066 & 0.089 & 0.120 & 0.011 & 0.008 & 0.003 & 0.003 \\
average & 0.022 & 0.006 & 0.010 & 0.016 & 0.003 & 0.002 & 0.0004 & 0.0003 \\
\hline
\end{tabular}

\subsection{Preliminary Analysis}

As illustrated in Figure 4, the direct stiffness coefficient $K_{t x, t x}$ has values in the range of $80-140 \mathrm{kN} \cdot \mathrm{m} / \mathrm{rad}$. Within the range under consideration, $K_{t x, t x}$ depends linearly on $\varepsilon_{x}$ and nonlinearly on $t_{x}, t_{y}, \dot{t}_{x}, \dot{t}_{y}$. The parameters $t_{x}, \dot{t}_{x}$, and $\varepsilon_{x}$ exhibit significant effects (more than $10 \%$ ). $K_{t x}, t x$ is almost insensitive to $t_{x}$ at low negative tilting angles; however, it decreases linearly with $t_{x}$ at positive and high negative tilting angles (see Figure 4a). The effect of the x-tilting velocity $\dot{t}_{x}$ is the diminishing of $K_{t x}, t x$, which is more significant at negative tilting angles. $K_{t x}, t x$ increases with decreasing $t_{y}$, increasing $\dot{t}_{y}$ and $\varepsilon_{x}$, and is insensible to $\varepsilon_{y}$ (see Figure $4 b, c$ ). 
(a)
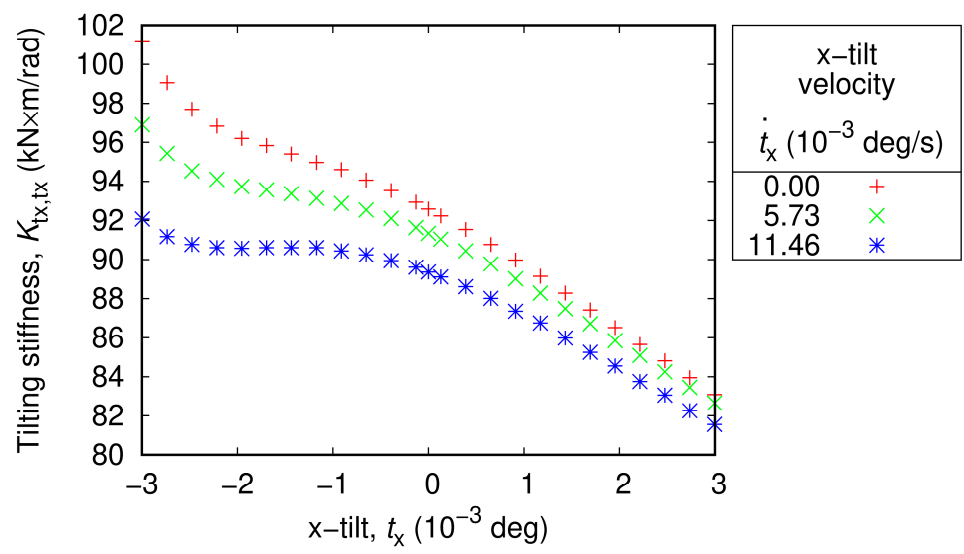

(b)
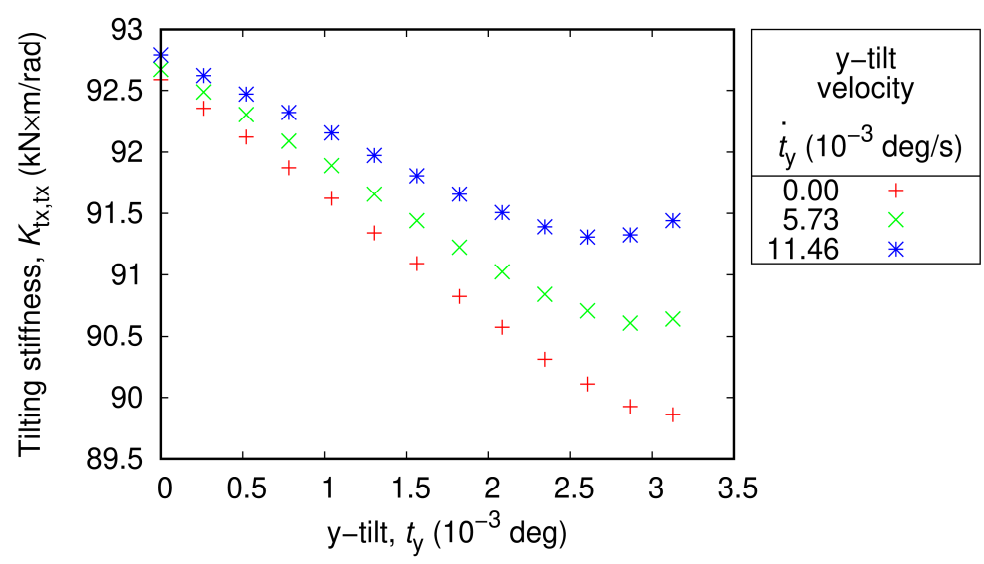

(c)

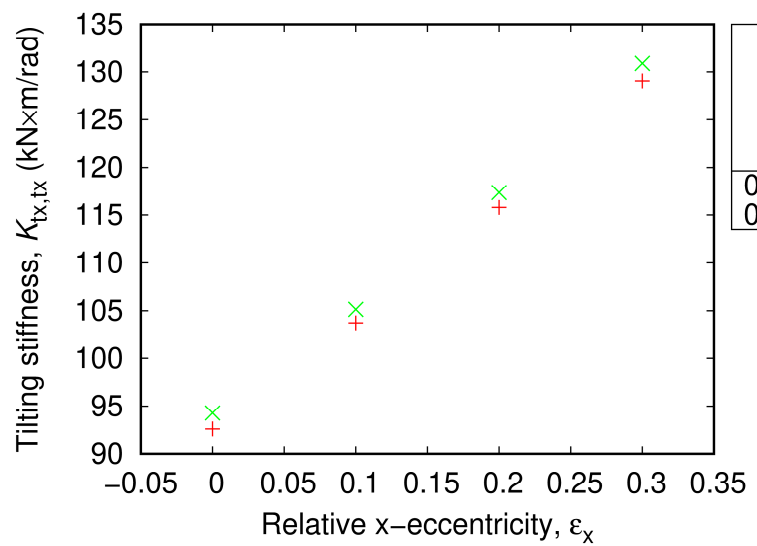

Relative

y-eccentricity

\begin{tabular}{|ll|} 
& $\varepsilon_{\mathrm{y}}$ \\
\hline 0.0 & + \\
0.1 & $\times$ \\
\hline
\end{tabular}

Figure 4. Parameter sensitivity of the direct stiffness coefficient $K_{t x, t x}$ : (a) Effects of the tilting angle and tilting velocity in the $x$-direction; (b) Effects of the tilting angle and tilting velocity in the $\mathrm{y}$-direction; (c) Effects of relative eccentricities. All unreferenced parameters have zero values.

The cross-coupled stiffness coefficient $K_{t x, t y}$ is approximately 10 times smaller than the direct stiffness coefficient $K_{t x, t x}$, and lies in the range of $6-15 \mathrm{kN} \cdot \mathrm{m} / \mathrm{rad}$ (see Figure 5). It is highly sensitive to all parameters, except for $\dot{t}_{x}$. $K_{t x, t y}$ increases with decreasing $t_{x}$ and $\dot{t}_{y}$, and increasing $t_{y}$ (see Figure $5 a, b$ ). Eccentricity $\varepsilon_{x}$ can increase or decrease $K_{t x, t y}$, depending on $\varepsilon_{y}$ (see Figure 5c). 
(a)

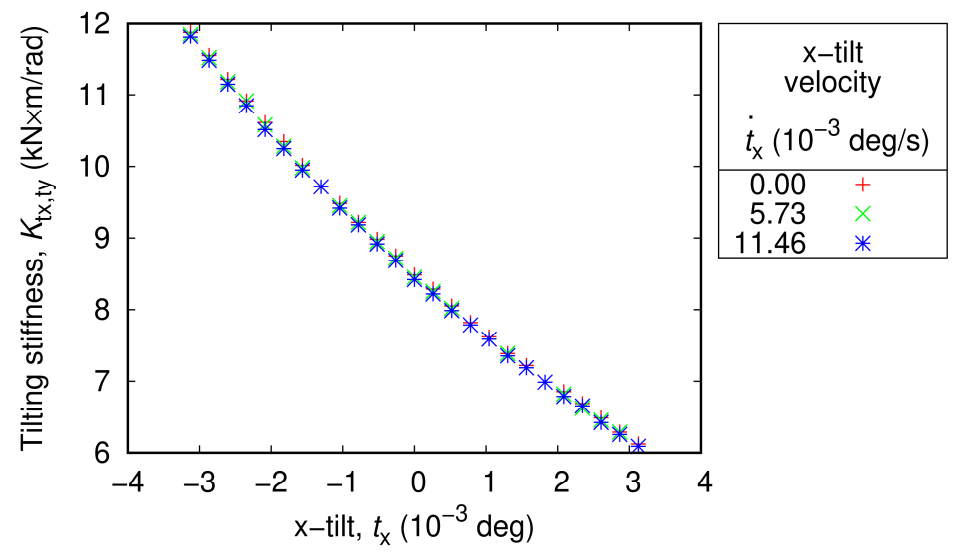

(b)
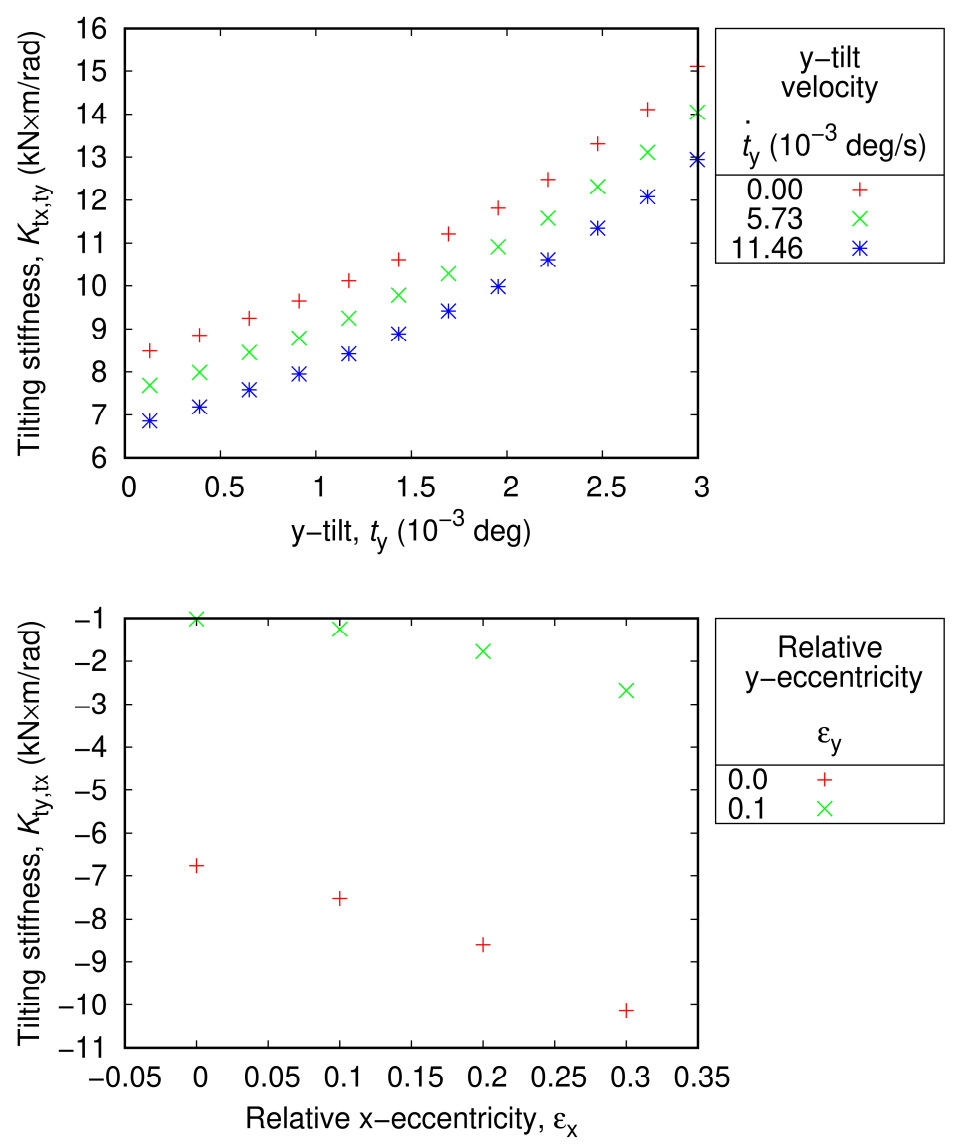

Figure 5. Parameter sensitivity of the cross-coupled stiffness coefficient $K_{t x, t y}$ : (a) Effects of tilting angle and tilting velocity in the x-direction; (b) Effects of the tilting angle and tilting velocity in the y-direction; (c) Effects of relative eccentricities. All unreferenced parameters have zero values.

$K_{t y, t x}$, which is another cross-coupled stiffness coefficient, is of the same order of magnitude; however, it is negative, and falls in the range of $-18-0 \mathrm{kN} \cdot \mathrm{m} / \mathrm{rad}$ (refer to Figure 6). It is not sensitive to $\dot{t}_{x}$, and the $\dot{t}_{y}$ effect on it is also negligible (see Figure 6a,b). The magnitude of $K_{t y, t x}$ is higher at lower $t_{x}$ and $\varepsilon_{y}$ and at higher $t_{y}$ and $\varepsilon_{x}$. 
(a)

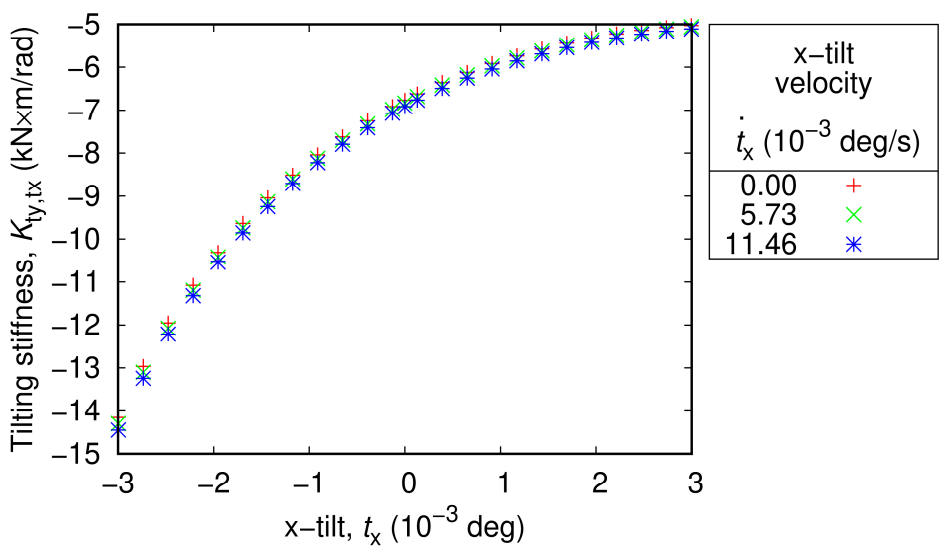

(b)
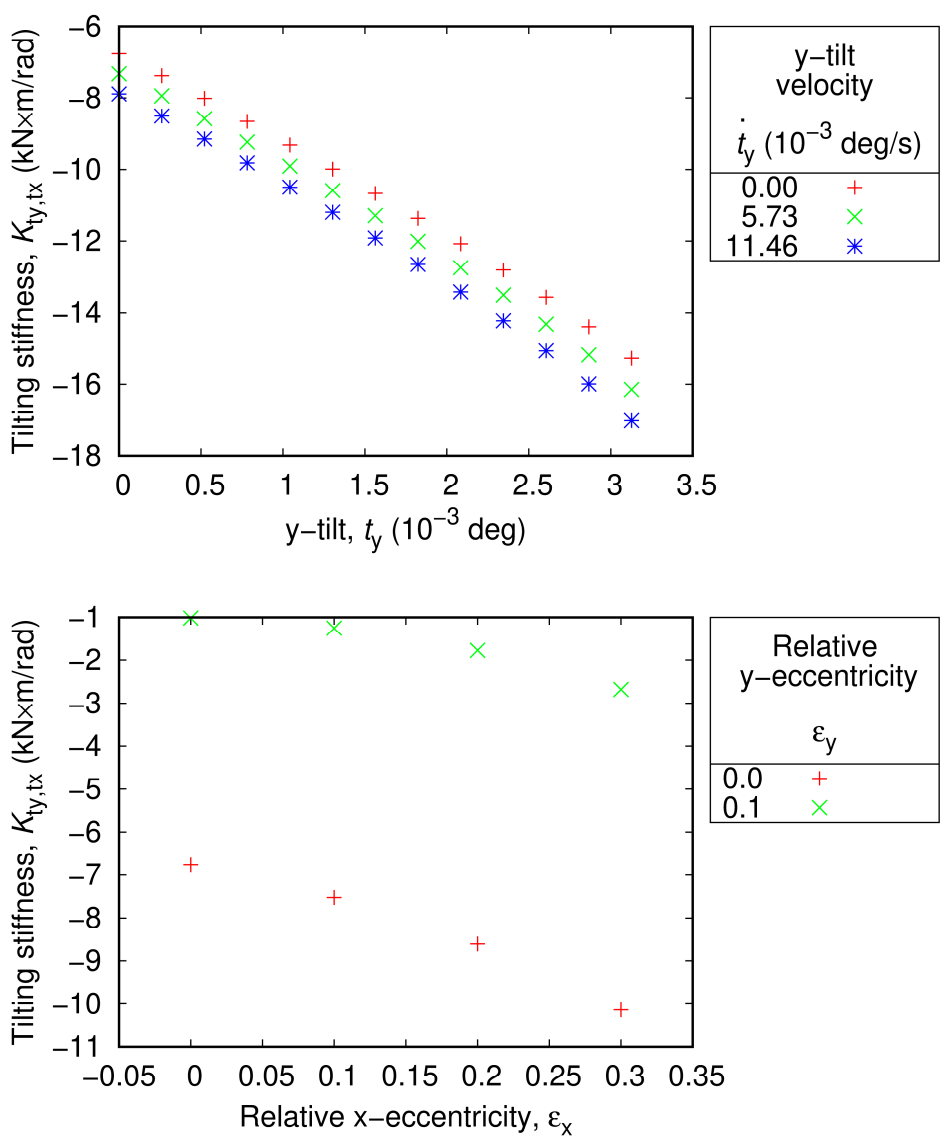

Figure 6. Parameter sensitivity of the cross-coupled stiffness coefficient $K_{t y, t x}$ : (a) Effects of the tilting angle and tilting velocity in the $x$-direction; (b) Effects of the tilting angle and tilting velocity in the y-direction; (c) Effects of relative eccentricities. All unreferenced parameters have zero values.

The direct stiffness coefficient $K_{t y, t y}$ is higher than that of $K_{t x, t x} . K_{t y, t y}$ falls in the range of $110-140 \mathrm{kN} \cdot \mathrm{m} / \mathrm{rad}$ (refer to Figure 7). This is triggered by the cut arc, which increases force and decreases the stiffness in the $x$-direction [27]. The y-tilting angle $t_{y}$ exerts a strong nonlinear effect on $K_{t y, t y}$. The stiffness coefficient $K_{t y, t y}$ is almost constant for a low positive $t_{y}$, and then increases with increasing $t_{y}$. In contrast to $K_{t x, t x}$, which is primarily sensitive to "its own" parameter $t_{x}$ and significantly less sensitive to $t_{y}$. $K_{t y, t y}$ is equally sensitive to both $t_{x}$ and $t_{y}$. In addition, it is equally sensitive to both higher $\varepsilon_{x}$ and $\varepsilon_{y}$, with a negligible $\dot{t}_{y}$ effect, and no $\dot{t}_{x}$ effect. Furthermore, it is higher for lower $t_{x}$ and higher $t_{y}, \varepsilon_{x}$, and $\varepsilon_{y}$. 
(a)

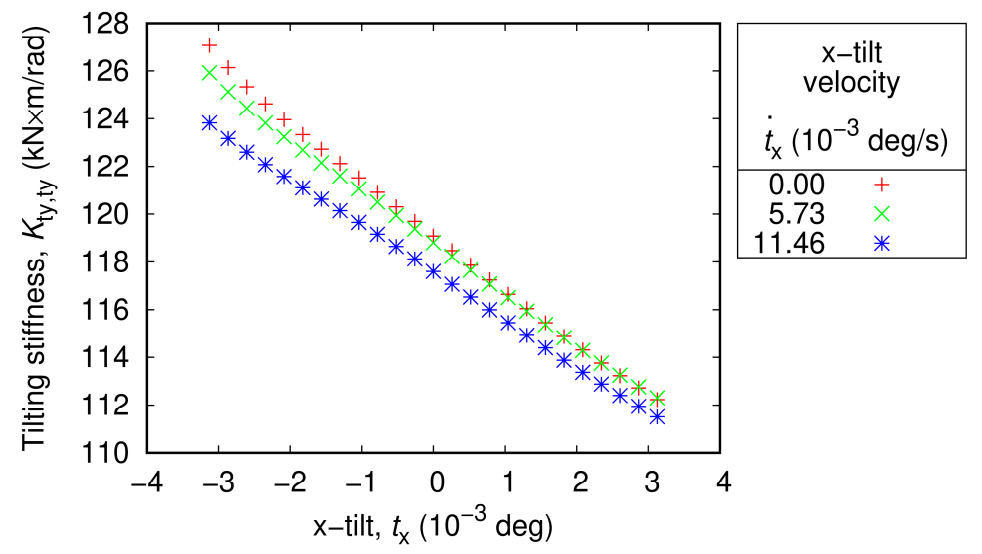

(b)
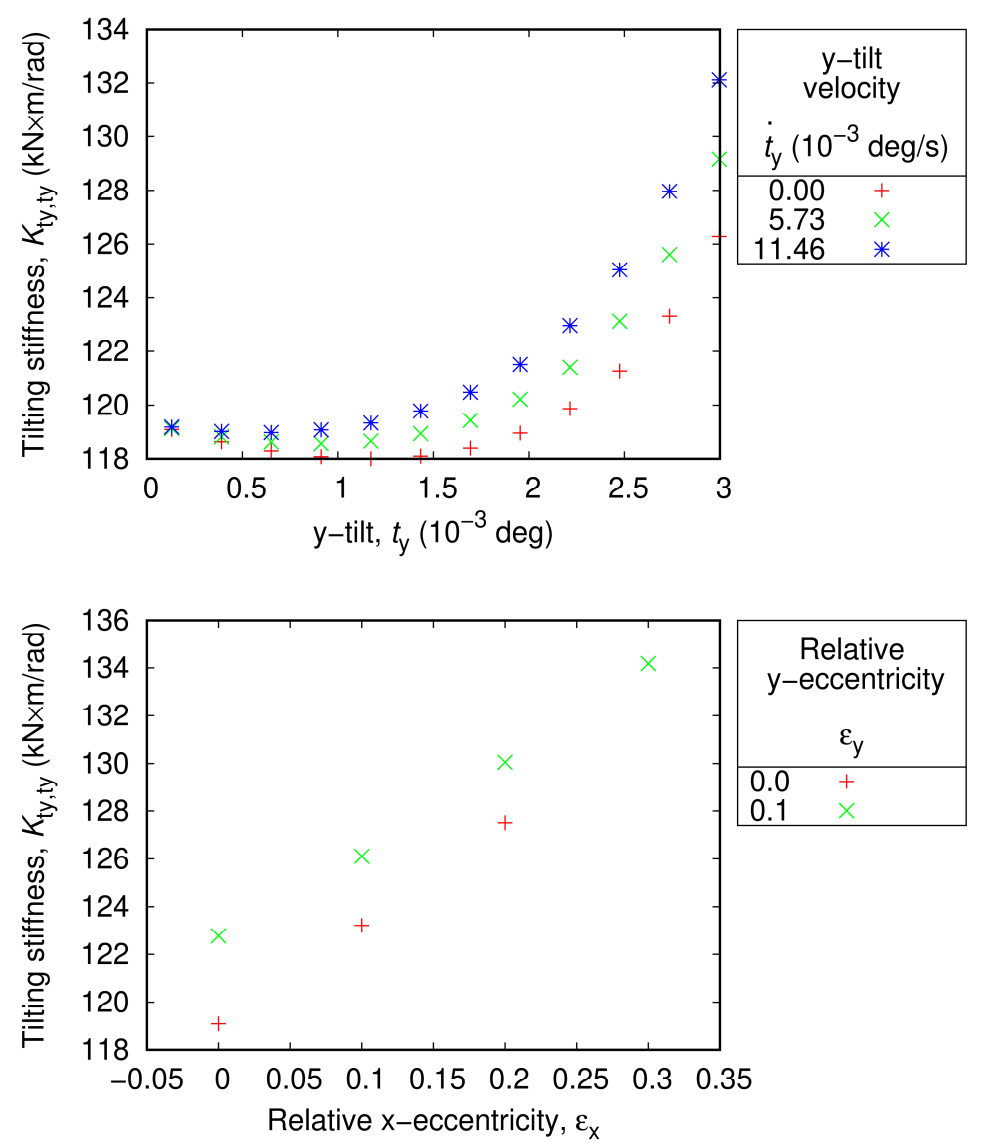

Figure 7. Parameter sensitivity of the direct stiffness coefficient $K_{t y, t y}$ : (a) Effects of the tilting angle and tilting velocity in the x-direction; (b) Effects of the tilting angle and tilting velocity in the y-direction; (c) Effects of relative eccentricities. All unreferenced parameters have zero values.

Because the simultaneous variation of tilting velocities was not studied, the effect of $\dot{t}_{x}$ was solely studied for $D_{t x, t x}$ and $D_{t y, t x}$, while the effect of $\dot{t}_{y}$ was solely studied for $D_{t x, t y}$ and $D_{t y, t y}$. Instead of the missing parameter, the coupling between $t_{x}$ and $t_{y}$ is comprehensively presented in Figures 8-11.

The direct damping coefficient $D_{t x, t x}$ is positive and falls in the range $0.2-2.2 \mathrm{kN} \cdot \mathrm{m} \mathrm{s} / \mathrm{rad}$ (refer to Figure 8). It is higher for lower $t_{x}$, and higher $t_{y}$ and higher $\dot{t}_{x}$ (see Figure $8 \mathrm{a}, \mathrm{b}$ ). The effect of eccentricity is also substantial, nonlinear, and strongly coupled between $\varepsilon_{x}$ and $\varepsilon_{y}$ (see Figure 8c). 
(a)
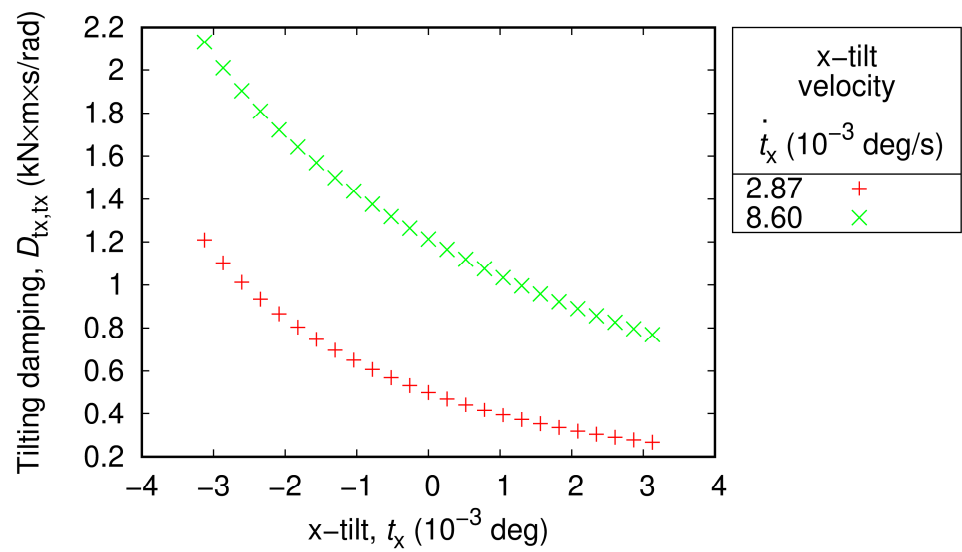

(b)

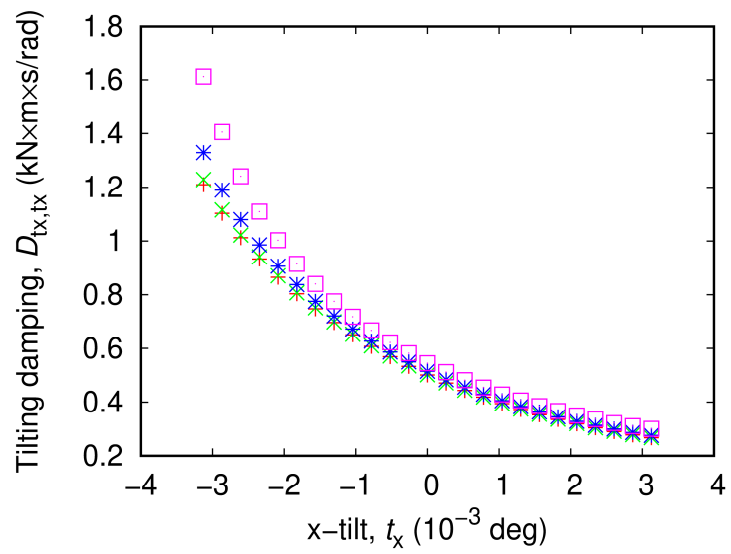

\begin{tabular}{|ll|}
\hline \multicolumn{2}{|c|}{ y-tilt } \\
$t_{\mathrm{y}}\left(10^{-3}\right.$ & deg $)$ \\
\hline 0.00 & + \\
1.04 & $\times$ \\
2.08 & $*$ \\
3.13 & $\square$ \\
\hline
\end{tabular}

(c)

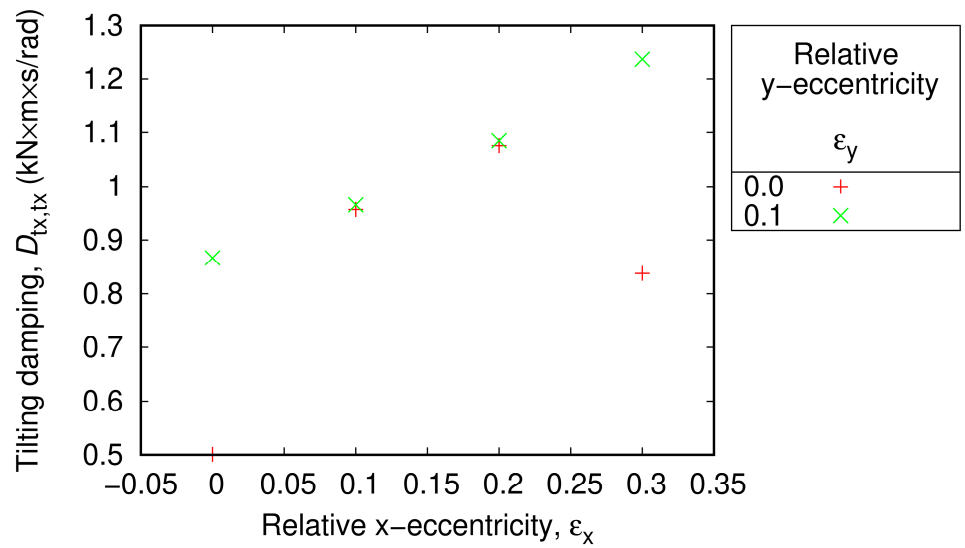

Figure 8. Parameter sensitivity of the direct damping coefficient $D_{t x, t x}$ : (a) Effects of the tilting angle and tilting velocity in the $x$-direction; (b) Effects of the $x$ and $y$ tilting angles; (c) Effects of the relative eccentricities. All unreferenced parameters have zero values.

The cross-coupled damping coefficient $D_{t x, t y}$ does not exceed $1 \mathrm{kN} \mathrm{m} \mathrm{s} / \mathrm{rad}$ in magnitude, being mostly negative (see Figure 9). $D_{t x, t y}$ rapidly decreases with decreasing $t_{x}$ or increasing $t_{y}$ in the negative $t_{x}$ range, while in the positive $t_{x}$ range, it is much less sensible both to $t_{x}$ and $t_{y}$ (see Figure 9 a). $D_{t x, t y}$ decreases with increasing $t_{y}$ and is almost insensible to $\dot{t}_{y}$ (see Figure $9 \mathrm{~b}$ ). The dependence of $D_{t x, t y}$ on eccentricity parameters is highly nonlinear. $D_{t x, t y}$ can take relatively high positive values for zero $\varepsilon_{x}$. and positive $\varepsilon_{y}$, but in most of the range, the sensitivity to $\varepsilon_{x}$ and $\varepsilon_{y}$ is low (see Figure 9c). 
(a)

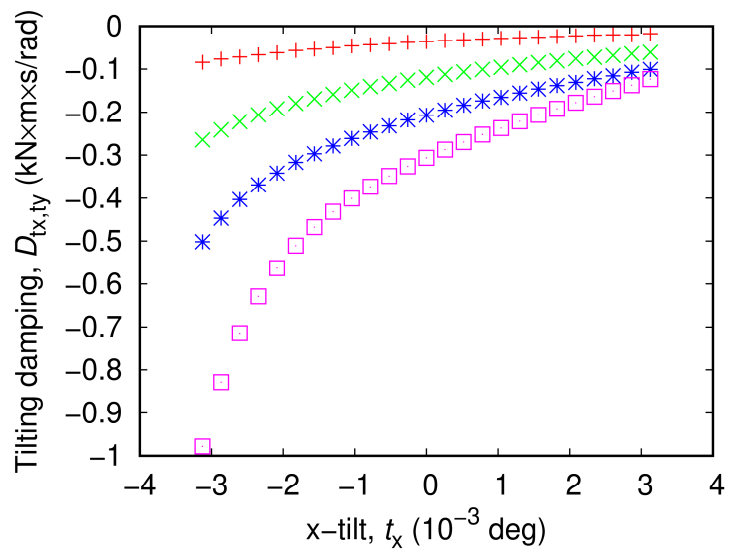

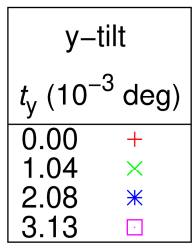

(b)
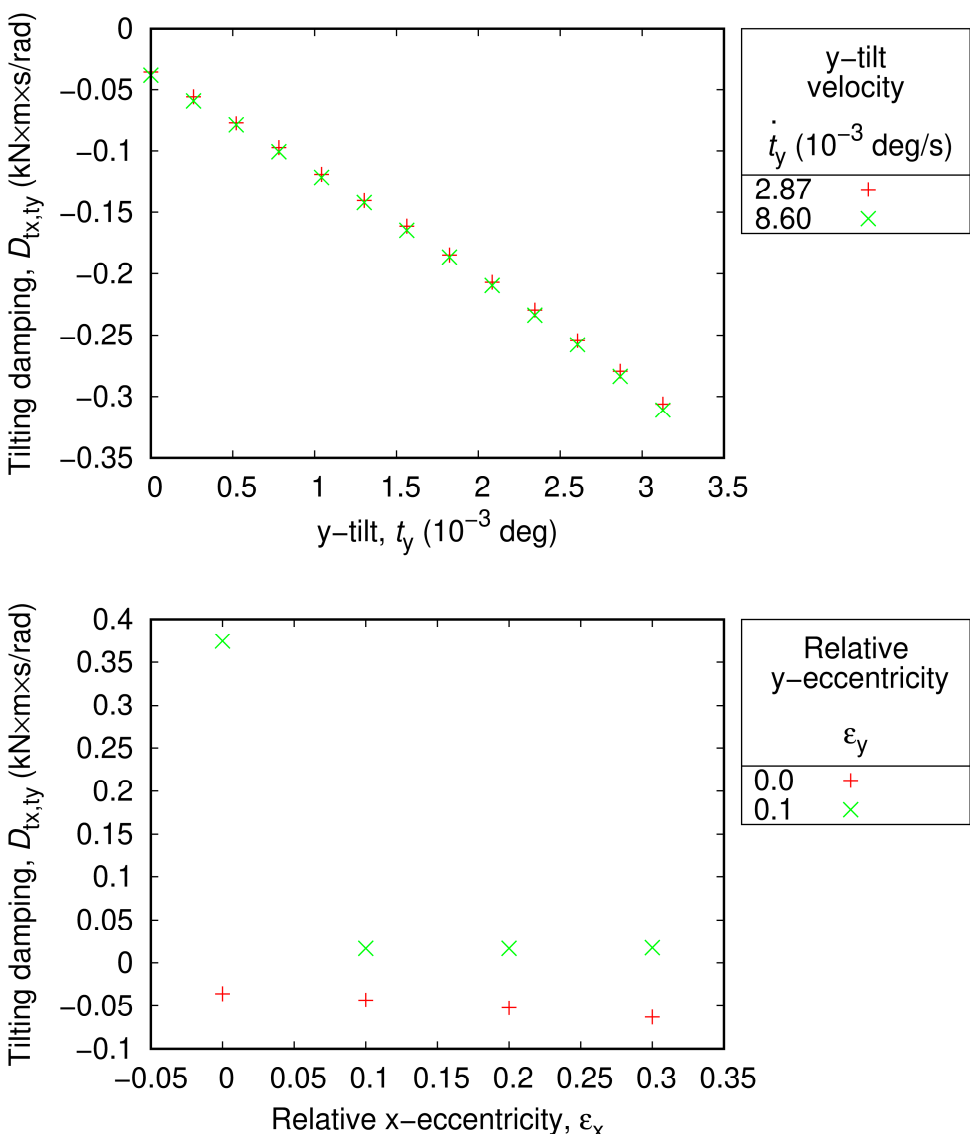

Relative y-eccentricity

(c)

Relative $\mathrm{x}$-eccentricity, $\varepsilon_{\mathrm{x}}$

Figure 9. Parameter sensitivity of the cross-coupled damping coefficient $D_{t x, t y}$ : (a) Effects of $x$ and $y$ tilting angles; (b) Effects of the tilting angle and tilting velocity in the y-direction; (c) Effects of relative eccentricities. All unreferenced parameters have zero values.

The cross-coupled damping coefficient $D_{t y}$,tx falls in the range $-0.6-0.13 \mathrm{kN} \mathrm{m} \mathrm{s} / \mathrm{rad}$ (see Figure 10). It is negative for positive $t_{y}$ and negative $t_{x}$, otherwise it is positive. Similar to $D_{t x, t y}, D_{t y, t x}$ rapidly decreases with decreasing $t_{x}$ or increasing $t_{y}$ in the negative $t_{x}$ range, while in the positive $t_{x}$ range, it is much less sensible both to $t_{x}$ and $t_{y}$. However, for $t_{x}>0.002^{\circ}, D_{t y, t x}$ increases with increasing $t_{y}$ (see Figure 10b), while $D_{t x, t y}$ decreases with increasing $t_{y}$ for any $t_{x}$ (see Figure $9 \mathrm{a}$ ). For zero $t_{y}, D_{t y, t x}$ decreases with increasing $t_{x}$ and decreasing $\dot{t}_{x}$. Similar to all previously considered damping coefficients, the dependence of $D_{t y, t x}$ on the eccentricity parameters is highly nonlinear. 
(a)
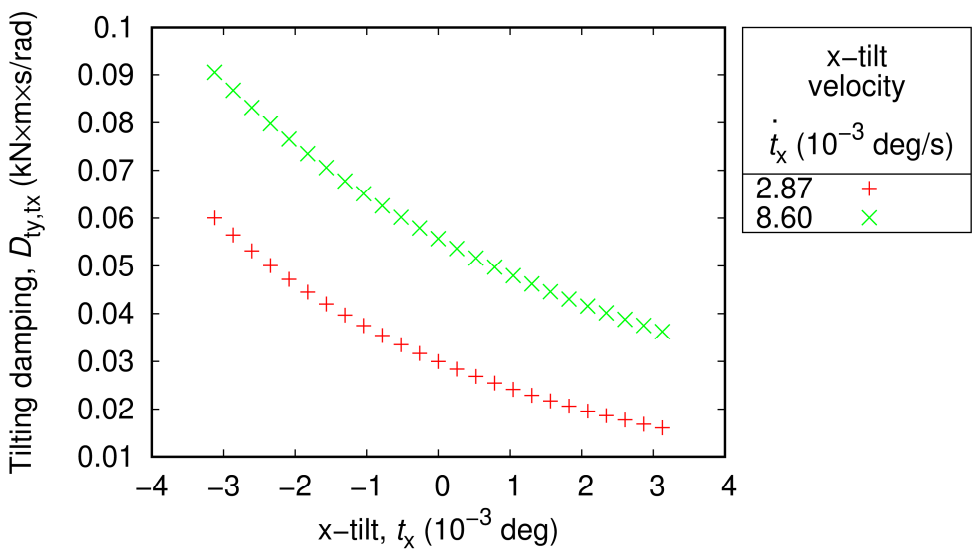

(b)

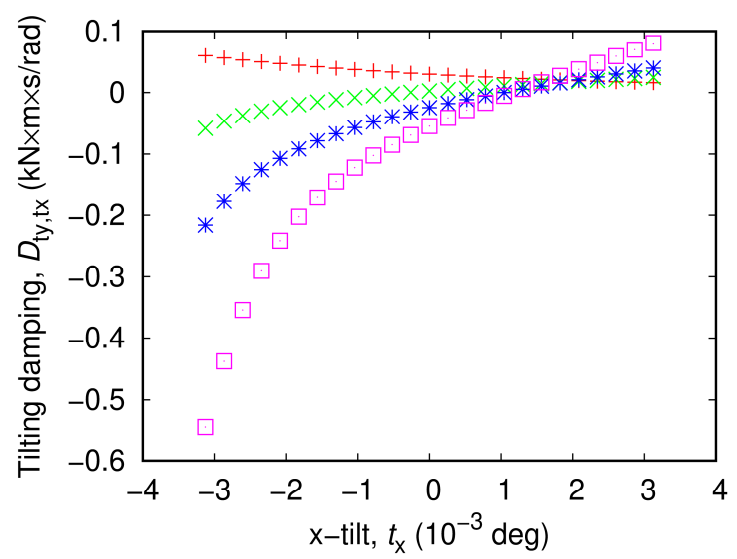

\begin{tabular}{|c|c|}
\hline \multicolumn{2}{|c|}{$\begin{array}{c}y-\text { tilt } \\
t_{y}\left(10^{-3} \text { deg }\right)\end{array}$} \\
\hline $\begin{array}{l}0.00 \\
1.04\end{array}$ & $\begin{array}{l}+ \\
\times\end{array}$ \\
\hline $\begin{array}{l}1.04 \\
2.08\end{array}$ & \\
\hline 3.13 & $\square$ \\
\hline
\end{tabular}

(c)

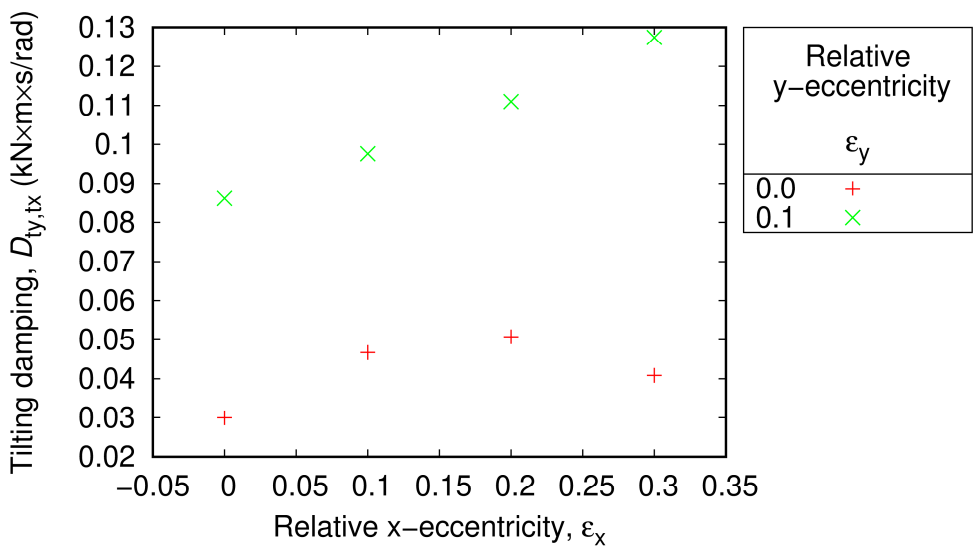

Figure 10. Parameter sensitivity of the cross-coupled damping coefficient $D_{t y, t x}$ : (a) Effects of the tilting angle and tilting velocity in the $x$-direction; (b) Effects of $x$ and $y$ tilting angles; (c) Effects of relative eccentricities. All unreferenced parameters have zero values.

In contrast with all other damping coefficients, the direct damping coefficient $D_{t y}, t y$ does not significantly depend on $\varepsilon_{x}$ and $\varepsilon_{y}$ (refer to Figure 11). It falls in the range $0.6-2.0 \mathrm{kN} \cdot \mathrm{m} \mathrm{s} / \mathrm{rad}$. It is higher for lower $t_{x}$, and higher $t_{y}$, similar to $D_{t x, t x} . D_{t y, t y}$ is almost insensible to the y-tilt velocity $\dot{t}_{y}$. It slightly increases with increasing $\varepsilon_{x}$ and increasing $\varepsilon_{y}$. 
(a)

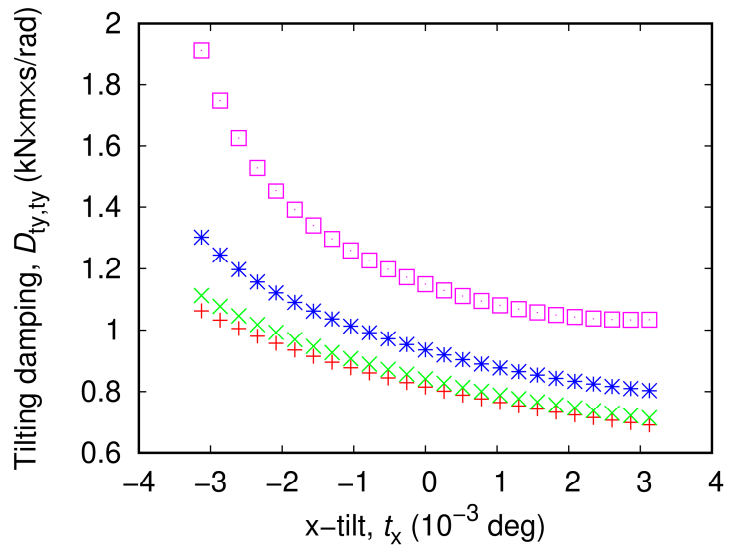

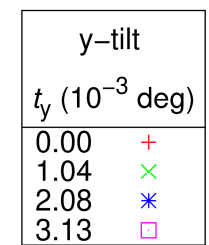

(b)
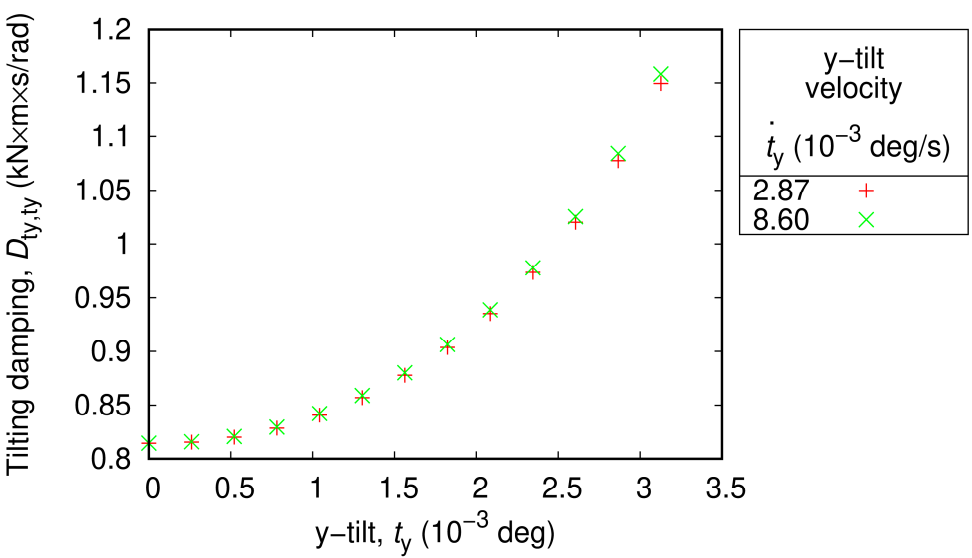

(c)

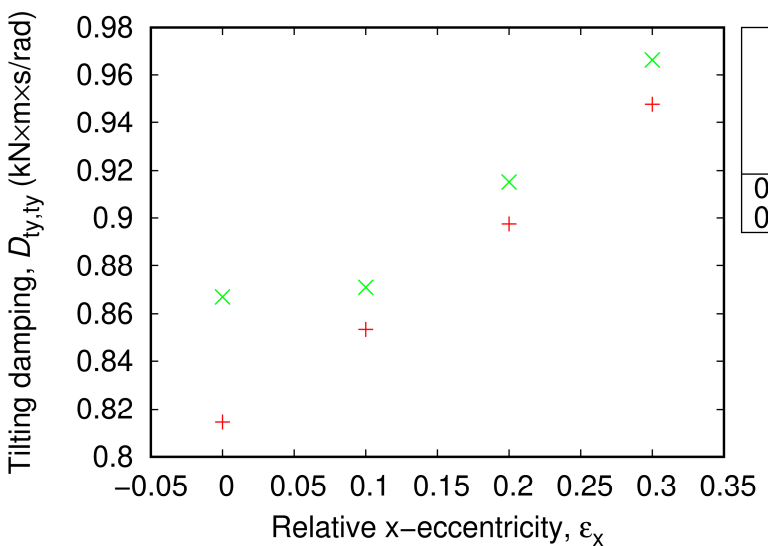

Relative y-eccentricity

\begin{tabular}{|ll} 
& $\varepsilon_{y}$ \\
\hline 0.0 & + \\
0.1 & $\times$ \\
\hline
\end{tabular}

Figure 11. Parameter sensitivity of the direct damping coefficient $D_{t y, t y}$ : (a) Effects of $x$ and $y$ tilting angles; (b) Effects of the tilting angle and tilting velocity in the y-direction; (c) Effects of relative eccentricities. All unreferenced parameters have zero values.

In summary, the direct stiffness and damping coefficients were positive. The crosscoupled stiffness coefficients are approximately 10 times smaller than the direct stiffness coefficients, and the cross-coupled damping coefficients are approximately 2-3 times smaller than the direct damping coefficients. Hence, a stable tilting motion was expected. However, information on the rotor inertia and the bearing at the other end is required to make precise conclusions on the dynamic behavior. Moreover, the results above exhibit a strong coupling between the eccentricity and tilting motion, including the nonlinearity of the moments relative to the position parameters. This can make the rotor motion severely complicated. 


\subsection{Regression}

Although it is possible to obtain the direct solution of the time-dependent problem in the model described above, the process is significantly time consuming because the air flow problem must be solved at every step. Conversely, the air-bearing forces and moments can be calculated using the interpolated stiffness and damping coefficients. In this study, each dynamic coefficient for each combination of $\varepsilon_{x}, \varepsilon_{y}, \dot{t}_{x}$, and $\dot{t}_{y}$ was first fitted with a quadratic polynomial of $t_{x}$ and $t_{y}$, and then each coefficient of the polynomial was fitted with a linear function of $\varepsilon_{x}, \varepsilon_{y}, \dot{t}_{x}$, and $\dot{t}_{y}$. The accuracy of the fitting is expressed in the form of determination coefficients, as presented in Table 2. The accuracy is relatively good, although it can be improved for $\widetilde{K}_{t x, t y}, \widetilde{D}_{t x, t x}, \widetilde{D}_{t x, t y}$, and $\widetilde{D}_{t y, t x}$ by providing more points and increasing the fitting order in $\varepsilon_{x}$ and $\varepsilon_{y}$ degrees of freedom.

Table 2. Coefficients of determination for dimensionless dynamic coefficient fitting.

\begin{tabular}{ccccccccc}
\hline & \multicolumn{3}{c}{ Stiffness (kN·m/rad) } & \multicolumn{4}{c}{ Damping (kN·m·s/rad) } \\
& $\tilde{K}_{t x, t x}$ & $\tilde{\boldsymbol{K}}_{t x, t y}$ & $\tilde{\boldsymbol{K}}_{t y, t x}$ & $\tilde{\boldsymbol{K}}_{t y, t y}$ & $\tilde{\boldsymbol{D}}_{t x, t x}$ & $\tilde{\boldsymbol{D}}_{t x, t y}$ & $\tilde{\boldsymbol{D}}_{t y, t x}$ & $\tilde{\boldsymbol{D}}_{t y, t y}$ \\
\hline $\mathrm{R}^{2}$ & 0.99 & 0.77 & 0.97 & 0.96 & 0.89 & 0.83 & 0.91 & 0.96 \\
\hline
\end{tabular}

The fitting results are presented in Tables 3-10. An example of the table interpretation is given below for $K_{t x, t x}$ :

$$
\begin{gathered}
\widetilde{K}_{t x, t x}=\left(1.09533+1.49129 \varepsilon_{x}+0.17719 \varepsilon_{y}-0.02161 \dot{T}_{x}\right)+ \\
\left(-0.30745-3.94666 \varepsilon_{x}+0.10915 \dot{T}_{x}+0.00478 \dot{T}_{y}\right) T_{x}+ \\
\left(-0.15003+0.09324 \varepsilon_{x}-1.16823 \varepsilon_{y}+0.01582 \dot{T}_{x}+0.0114 \dot{T}_{y}\right) T_{y}+ \\
\left(-0.3232+2.45267 \varepsilon_{x}+2.42515 \varepsilon_{y}+0.16265 \dot{T}_{x}-0.28434 \dot{T}_{y}\right) T_{x} T_{y}+ \\
\left(7.99445 \varepsilon_{x}-0.26854 \varepsilon_{y}-0.35236 \dot{T}_{x}+0.14364 \dot{T}_{y}\right) T_{x}^{2}+ \\
\left(0.34256+0.41188 \varepsilon_{x}+1.09915 \varepsilon_{y}-0.13117 \dot{T}_{x}+0.17535 \dot{T}_{y}\right) T_{y}^{2}
\end{gathered}
$$

Table 3. Fitting results for $\widetilde{K}_{t x, t x}$.

\begin{tabular}{cccccc}
\hline & $\mathbf{1}$ & $\varepsilon_{x}$ & $\varepsilon_{y}$ & $\dot{\boldsymbol{T}}_{x}$ & $\dot{\boldsymbol{T}}_{y}$ \\
\hline 1 & 1.09533 & 1.49129 & 0.17719 & -0.02161 & 0 \\
$T_{x}$ & -0.30745 & -3.94666 & 0 & 0.10915 & 0.00478 \\
$T_{y}$ & -0.15003 & 0.09324 & -1.16823 & 0.01582 & 0.0114 \\
$T_{x} T_{y}$ & -0.3232 & 2.45267 & 2.42515 & 0.16265 & -0.28434 \\
$T_{x}^{2}$ & 0 & 7.99445 & -0.26854 & -0.35236 & 0.14364 \\
$T_{y}^{2}$ & 0.34256 & 0.41188 & 1.09915 & -0.13117 & 0.17535 \\
\hline
\end{tabular}

Table 4. Fitting results for $\widetilde{K}_{t x, t y}$.

\begin{tabular}{cccccc}
\hline & $\mathbf{1}$ & $\varepsilon_{x}$ & $\varepsilon_{y}$ & $\dot{T}_{x}$ & $\dot{\boldsymbol{T}}_{y}$ \\
\hline 1 & 0.10973 & 0 & 0.51941 & -0.00802 & -0.02162 \\
$T_{x}$ & -0.13722 & -0.006 & -0.80745 & 0 & -0.02419 \\
$T_{y}$ & 0 & -1.68577 & -0.42286 & 0.08025 & 0.193 \\
$T_{x} T_{y}$ & 0.22904 & 3.62763 & -2.10164 & 0 & 0.74463 \\
$T_{x}^{2}$ & -0.1213 & 1.02097 & 1.42966 & 0.06678 & -0.15351 \\
$T_{y}^{2}$ & 0.50093 & 3.62374 & -2.3118 & 0 & -0.34029 \\
\hline
\end{tabular}


Table 5. Fitting results for $\widetilde{K}_{t y, t x}$.

\begin{tabular}{cccccc}
\hline & $\mathbf{1}$ & $\boldsymbol{\varepsilon}_{\boldsymbol{x}}$ & $\boldsymbol{\varepsilon}_{\boldsymbol{y}}$ & $\dot{\boldsymbol{T}}_{\boldsymbol{x}}$ & $\dot{\boldsymbol{T}}_{\boldsymbol{y}}$ \\
\hline 1 & -0.07381 & -0.09673 & 0.78029 & -0.00428 & -0.00686 \\
$T_{x}$ & 0.11042 & 0.41995 & -1.26002 & 0.01449 & 0.00965 \\
$T_{y}$ & -0.24779 & -1.11043 & 0.33455 & 0.02062 & 0.02685 \\
$T_{x} T_{y}$ & 1.06605 & 2.90228 & 0 & -0.20887 & 0.24493 \\
$T_{x}^{2}$ & -0.72174 & -0.86434 & 1.50162 & 0.07247 & -0.11828 \\
$T_{y}^{2}$ & -0.6127 & 0.69547 & 0.93397 & 0.10771 & -0.20109 \\
\hline
\end{tabular}

Table 6. Fitting results for $\widetilde{K}_{t y, t y}$.

\begin{tabular}{cccccc}
\hline & $\mathbf{1}$ & $\varepsilon_{x}$ & $\mathcal{E}_{y}$ & $\dot{\boldsymbol{T}}_{\boldsymbol{x}}$ & $\dot{\boldsymbol{T}}_{\boldsymbol{y}}$ \\
\hline 1 & 1.42569 & 0.47905 & 0.29851 & 0 & 0.0155 \\
$T_{x}$ & -0.30423 & -1.10565 & 0 & 0.0651 & 0.12299 \\
$T_{y}$ & -0.64244 & 0.25697 & -3.21467 & 0 & -0.10432 \\
$T_{x} T_{y}$ & -1.01131 & 0 & 5.08434 & 0.17214 & -0.52047 \\
$T_{x}^{2}$ & 0.43263 & 1.33588 & 0 & -0.03328 & 0.27025 \\
$T_{y}^{2}$ & 3.53634 & 1.57983 & 2.17612 & -0.13259 & 0.69417 \\
\hline
\end{tabular}

Table 7. Fitting results for $\widetilde{D}_{t x, t x}$.

\begin{tabular}{cccccc}
\hline & $\mathbf{1}$ & $\boldsymbol{\varepsilon}_{\boldsymbol{x}}$ & $\boldsymbol{\varepsilon}_{\boldsymbol{y}}$ & $\dot{\boldsymbol{T}}_{\boldsymbol{x}}$ & $\dot{\boldsymbol{T}}_{\boldsymbol{y}}$ \\
\hline 1 & 0.0097 & 0.00358 & 0 & 0.00156 & 0 \\
$T_{x}$ & -0.02028 & -0.05093 & 0 & -0.00117 & 0 \\
$T_{y}$ & -0.00168 & -0.00288 & -0.01683 & 0.00023 & 0 \\
$T_{x} T_{y}$ & -0.01595 & -0.04394 & 0.09286 & 0.00158 & 0 \\
$T_{x}^{2}$ & 0.03404 & 0.19438 & 0 & -0.00225 & 0 \\
$t_{y}^{2}$ & 0.01708 & 0.04876 & -0.01605 & -0.0015 & 0 \\
\hline
\end{tabular}

Table 8. Fitting results for $\widetilde{D}_{t x, t y}$.

\begin{tabular}{cccccc}
\hline & $\mathbf{1}$ & $\boldsymbol{\varepsilon}_{x}$ & $\boldsymbol{\varepsilon}_{y}$ & $\dot{\boldsymbol{T}}_{\boldsymbol{x}}$ & $\dot{\boldsymbol{T}}_{\boldsymbol{y}}$ \\
\hline 1 & 0.0024 & -0.00962 & 0.01265 & 0 & -0.00171 \\
$T_{x}$ & -0.00299 & 0.01579 & -0.02654 & 0 & 0.00227 \\
$T_{y}$ & -0.00896 & -0.01581 & 0 & 0 & 0.00029 \\
$T_{x} T_{y}$ & 0.03654 & 0.10701 & -0.05103 & 0 & 0.00167 \\
$T_{x}^{2}$ & -0.00931 & -0.05237 & 0.05414 & 0 & -0.00165 \\
$T_{y}^{2}$ & -0.01297 & -0.03191 & 0.06242 & 0 & -0.0018 \\
\hline
\end{tabular}

Table 9. Fitting results for $\widetilde{D}_{t y, t x}$.

\begin{tabular}{cccccc}
\hline & $\mathbf{1}$ & $\boldsymbol{\varepsilon}_{\boldsymbol{x}}$ & $\boldsymbol{\varepsilon}_{\boldsymbol{y}}$ & $\dot{\boldsymbol{T}}_{\boldsymbol{x}}$ & $\dot{\mathrm{T}}_{\boldsymbol{y}}$ \\
\hline 1 & 0.00072 & 0.00114 & 0.00674 & 0 & 0 \\
$T_{x}$ & -0.00151 & -0.00441 & -0.01802 & 0 & 0 \\
$T_{y}$ & -0.00833 & 0 & -0.01345 & -0.00208 & 0 \\
$T_{x} T_{y}$ & 0.03325 & 0.08433 & -0.02828 & 0 & 0 \\
$T_{x}^{2}$ & -0.00695 & -0.01593 & 0.04641 & 0 & 0 \\
$T_{y}^{2}$ & -0.00795 & -0.01552 & 0.0475 & 0.00093 & 0 \\
\hline
\end{tabular}


Table 10. Fitting results for $\widetilde{D}_{t y, t y}$.

\begin{tabular}{cccccc}
\hline & $\mathbf{1}$ & $\boldsymbol{\varepsilon}_{\boldsymbol{x}}$ & $\boldsymbol{\varepsilon}_{\boldsymbol{y}}$ & $\dot{\boldsymbol{T}}_{\boldsymbol{x}}$ & $\dot{\boldsymbol{T}}_{\boldsymbol{y}}$ \\
\hline 1 & 0.00987 & 0.00426 & 0.00289 & 0 & -0.00014 \\
$T_{x}$ & -0.00619 & -0.01127 & -0.0017 & 0 & 0.00026 \\
$T_{y}$ & -0.00943 & 0.01182 & -0.04927 & 0 & 0.00208 \\
$T_{x} T_{y}$ & -0.01952 & -0.05093 & 0.10336 & 0 & -0.00248 \\
$T_{x}^{2}$ & 0.01514 & 0.04059 & -0.01941 & 0 & 0.0007 \\
$T_{y}^{2}$ & 0.06967 & 0.05133 & -0.07676 & 0 & 0.00259 \\
\hline
\end{tabular}

Here, the dimensionless variables are adopted:

$$
\begin{gathered}
\frac{K_{i, j}}{\widetilde{K}_{i, j}}=\frac{p_{0} D L^{3}}{16 \mathrm{c}}=83,187 \frac{\mathrm{N} \mathrm{m}}{\mathrm{rad}} \\
\frac{D_{i, j}}{\widetilde{D}_{i, j}}=\frac{p_{0} D L^{2}}{2\left(0.0001 \frac{\mathrm{rad}}{\mathrm{s}}\right)}=1.51 \times 10^{5} \frac{\mathrm{N} \mathrm{m} \mathrm{s}}{\mathrm{rad}} \\
\frac{t_{x}}{T_{x}}=\frac{t_{y}}{T_{y}}=\frac{c}{L}=0.000182 \mathrm{rad}=0.0104^{\circ} \\
\frac{\dot{t}_{x}}{\dot{T}_{x}}=\frac{\dot{t}_{y}}{\dot{T}_{y}}=0.0001 \frac{\mathrm{rad}}{\mathrm{s}}=0.00573^{\circ} \frac{1}{\mathrm{~s}}
\end{gathered}
$$

\section{Discussion}

The tilting stiffness and damping analyzed in this study could be significant for the spindle shaft tilting motion, provided the shaft length is not significantly longer than the bearing length. Otherwise, the shaft tilting will be controlled by the air-bearing force applied at a long distance from the shaft center, while the tilting stiffness and damping will influence the shaft bending. In addition, bending can also significantly influence the air-bearing forces, moments, and dynamic coefficients, because of the convexity and concavity of the bearing surface $[14,23]$. Based on the obtained results, the tilting motion is independently stable because the direct stiffness and damping coefficients are positive and significantly higher in amplitude than the cross-coupled coefficients. However, the tilting dynamic coefficients were substantially influenced by shaft eccentricity. Hence, the stability of the shaft parallel and tilting motions must be analyzed together. The increased rotor speed would result in a more pronounced hydrodynamic component in the bearing forces, moments, stiffness, and damping components, as well as in more significant $x-y$ coupling, that is typical for the journal bearings.

\section{Conclusions}

The problem of tilting stiffness and damping analysis is hardly ever addressed in the literature since the fundamental books on rotodynamic and tribology where the theoretical analysis was presented for idealized types of bearings. This ignorance can be explained by the minor role of individual bearing moments, compared to the total shaft-bearing systems moments in most applications. However, the tilting moments exist, and they become more and more important in high-precision machinery. Besides the bearing moments, the tilting motion greatly affects the bearing forces, as well as other types of air film distortions, which are widely considered in recent publications.

The purpose of this study was to predict the behavioral characteristics according to the design and operating parameters of porous aerostatic bearings that can be utilized in applications requiring high-precision positioning, such as semiconductor manufacturing equipment. Most importantly, the highly efficient and reliable numerical analysis approach 
proposed in this study can contribute to increasing system stability and reducing costs and risks at the product level prior to the actual manufacturing process.

Author Contributions: Conceptualization, P.H. and P.K.; methodology, P.K.; software, P.K.; validation, P.H. and P.K.; formal analysis, P.K.; investigation, P.H. and P.K.; resources, P.H. and P.K.; data curation, P.H.; writing—original draft preparation. P.K.; writing-review and editing. P.H. and S.-W.K.; visualization, P.K.; supervision, P.H.; project administration, P.H.; funding acquisition, P.H. and S.-W.K. All authors have read and agreed to the published version of the manuscript.

Funding: This work was partly supported by Korea Institute for Advancement of Technology (KIAT) grant funded by the Korea Government (MOTIE) (P0002092, The Competency Development Program for Industry Specialist) and Korea Institute of Energy Technology Evaluation and Planning (KETEP) grant funded by the Korea Government (MOTIE) (20214000000010, Gyeongbuk Regional Wind Energy Cluster Human Resources Development Project) and State Assignment Project (No. FWEU-2021-0005) of the Fundamental Research Program of the Russian Federation 2021-2030.

Informed Consent Statement: Not applicable.

Data Availability Statement: Data are available by request.

Acknowledgments: The research was performed with use of the equipment of High-Temperature Circuit Multi-Access Research Center (Project No. 13.ЦКП.21.0038).

Conflicts of Interest: The authors declare no conflict of interest.

\section{References}

1. Akilian, M.; Forest, C.R.; Slocum, A.H.; Trumper, D.L.; Schattenburg, M.L. Thin optic constraint. Precis. Eng. 2007, 31, 130-138. [CrossRef]

2. New Way Air Bearings. Air Bearing Application and Design Guide; IBS Precision Engineering: Eindhoven, The Netherlands, 2006.

3. Khim, G.; Park, C.H. A rotary stage in a vacuum using an air bearing. Vacuum 2014, 105, 39-45. [CrossRef]

4. Andres, L.S.; Cable, T.A.; Zheng, Y.; De Santiago, O.; Devitt, D. Assessment of Porous Type Gas Bearings: Measurements of Bearing Performance and Rotor Vibrations. In Proceedings of the ASME Turbo Expo 2016: Turbomachinery Technical Conference and Exposition, Seoul, Korea, 13-17 June 2016. No. V07BT31A031.

5. Gao, Q.; Chen, W.; Lu, L.; Huo, D.; Cheng, K. Aerostatic bearings design and analysis with the application to precision engineering: State-of-the-art and future perspectives. Tribol. Int. 2019, 135, 1-17. [CrossRef]

6. Cappa, S.; Reynaerts, D.; Al-Bender, F. Reducing the Radial Error Motion of an aerostatic Journal Bearing to a Nanometer Level: Theoretical Modelling. Tribol. Let. 2014, 53, 27-41. [CrossRef]

7. Lie, K.N.; Su, J.C. A numerical analysis of optimum air journal bearings. J. Aeronaut. Astronaut. Aviation. Ser. A 2014, 46, 49-60.

8. Hosokawa, T.; Somaya, K.; Miyatake, M.; Yoshimoto, S. Static characteristics of aerostatic thrust bearings with multiple porous inlet ports. J. Tribol. 2015, 137, 1-8. [CrossRef]

9. Zhong, W.; Li, X.; Tao, G.L.; Kagawa, T. Measurement and Determination of Friction Characteristic of Air Flow through Porous Media. Metals 2015, 5, 336-349. [CrossRef]

10. Belforte, G.; Raparelli, T.; Viktorov, V.; Trivella, A. Permeability and Inertial Coefficients of Porous Media for Air Bearing Feeding Systems. ASME J. Tribol. 2007, 129, 705-711. [CrossRef]

11. Zhong, W.; Li, X.; Liu, F.H.; Tao, G.L.; Lu, B.; Kagawa, T. Measurement and Correlation of Pressure Drop Characteristics for Air Flow Through Sintered Metal Porous Media. Transp. Porous Media 2014, 101, 53-67. [CrossRef]

12. Zeng, C.; Wang, W.; Cheng, X.; Zhao, R.; Cui, H. Three-dimensional flow state analysis of microstructures of porous graphite restrictor in aerostatic bearings. Tribol. Int. 2021, 159, 106955. [CrossRef]

13. Huang, T.Y.; Shen, S.C.; Lin, S.C.; Hsu, S.Y. Pressure Distribution in the Air Film and the Porous Conveyor Air Bearing. Appl. Mech. Mater. 2014, 479, 380-384. [CrossRef]

14. Cui, H.; Wang, Y.; Yue, X.; Huang, M.; Wang, W. Effects of manufacturing errors on the static characteristics of aerostatic journal bearings with porous restrictor. Tribol. Int. 2017, 115, 246-260. [CrossRef]

15. Wang, W.; Cheng, X.; Zhang, M.; Gong, W.; Cui, H. Effect of the deformation of porous materials on the performance of aerostatic bearings by fluid-solid interaction method. Tribol. Int. 2020, 150, 106391. [CrossRef]

16. Van Ostayen, R.A.J.; Van Beek, A.; Munnig-Schmidt, R. Design and Optimization of an Active Aerostatic Thrust Bearing. In Proceedings of the ASPE, Dallas, TX, USA, 14-19 October 2007.

17. Hwang, P.; Khan, P.V. Non-Iterative Finite Element Scheme for Combined Annular-Thrust Porous Aerostatic Bearings Analysis. In Proceedings of the ASME/STLE International Joint Tribology Conference, Denver, CO, USA, 7-10 October 2017.

18. Plante, J.S.; Vogan, J.; El-Aguizy, T.; Slocum, A.H. A design model for circular porous air bearings using the 1D generalized flow method. Prec. Eng. ISPEN J. 2005, 29, 336-346. [CrossRef] 
19. Otsu, Y.; Miyatake, M.; Yoshimoto, S. Dynamic Characteristics of Aerostatic Porous Journal Bearings with a Surface Restricted Layer. ASME J. Tribol. 2011, 133, 011701-1. [CrossRef]

20. Zhang, X.; Lin, B. Theoretical research on deformation of porous material in air bearing. Appl. Mech. Mater. 2012, 215-216, 779-784. [CrossRef]

21. Yoshimoto, S.; Kohno, K. Static and Dynamic Characteristics of Aerostatic Circular Porous Thrust Bearings (Effect of the Shape of the Air Supply Area). ASME J. Tribol. 2001, 123, 501-508. [CrossRef]

22. Su, J.C.T.; Lie, K.N. Rotor dynamic instability analysis on hybrid air journal bearings. Tribol. Int. 2006, 39, 238-248. [CrossRef]

23. Cui, H.; Wang, Y.; Yue, X.; Li, Y.; Jiang, Z. Numerical analysis of the dynamic performance of aerostatic thrust bearings with different restrictors. Proc. Inst. Mech. Eng. Part J. Eng. Tribol. 2019, 233, 406-423. [CrossRef]

24. Zang, Y.; Hatch, M.R. Analysis of Coupled Journal and Thrust Hydrodynamic Bearing using Finite Volume Method. ASME Adv. Inf. Storage Process. Syst. 1995, 1, 71-79.

25. Rahman, M.; Leuthold, H. Computer simulation of a coupled journal and thrust hydrodynamic bearing using a Finite-Element Method. ASME Adv. Inf. Storage Process. Syst. 1996, 2, 103.

26. Wang, Y.; Wang, Q.J.; Lin, C. Mixed Lubrication of Coupled Journal-Thrust-Bearing Systems Including Mass Conserving Cavitation. ASME J. Tribol. 2003, 125, 747-755. [CrossRef]

27. Hwang, P.; Khan, P.V. Static Study of the Arc Effect on Annular-Thrust Aerostatic Porous Bearings. In Proceedings of the 5th World Tribology Congress (WTC 2013), Torino, Italy, 8-13 September 2013. 